\title{
Using wearable technology to monitor exercise intensity and predict $\dot{\mathrm{V}}_{2 \max }$
}

\author{
Robert W. Pettitt ${ }^{1}$, Sarah K. Fretti ${ }^{1}$, Michael A. Kantor ${ }^{1}$, Coral Gubler ${ }^{2}$ \\ ${ }^{1}$ Office of Research \& Sponsored Projects, ${ }^{2}$ Department of Physical Therapy, Rocky Mountain University of Health Professions, Provo, Utah, USA \\ Correspondence to: Robert W. Pettitt. Office of Research \& Sponsored Projects, Rocky Mountain University of Health Professions, 561 E 1860 S, \\ Provo, Utah 84606, USA. Email: robert.pettitt@rm.edu. \\ Comment on: Freeberg KA, Baughman BR, Vickey T, et al. Assessing the ability of the Fitbit Charge 2 to accurately predict $\dot{\mathrm{VO}}_{2 \max }$. $\mathrm{mHealth}$ \\ 2019;5:39.
}

Received: 11 December 2019; Accepted: 07 January 2020; Published: 20 April 2021.

doi: $10.21037 /$ mhealth.2020.01.03

View this article at: http://dx.doi.org/10.21037/mhealth.2020.01.03

\section{Introduction}

Wearable technology is an exciting and inexpensive method for monitoring training intensities and providing data for performance testing. In the case of the FitBit Charge 2 (FBC2) device, the parameters of speed, distance, and heart rate (HR) can be monitored and downloaded by the user. In the present Editorial Commentary, we discuss a recent study by Freeberg et al. (1). These investigators examined the validity of the FBC2 device and the manufacturer's protocol for estimating maximum oxygen uptake $\left(\dot{\mathrm{V}}_{2 \max }\right)$.

Our commentary focuses on the technique that the FBC2 uses to predict maximum oxygen uptake $\left(\dot{\mathrm{V}}_{2 \max }\right)$. Rather than rely on exercising HR along with distance and time, we recommend wearable manufacturers consider a method of predicting $\dot{\mathrm{V}} \mathrm{O}_{2 \max }$ based off of an estimate of critical speed (CS). The utilization of a time-trial (i.e., fastest time elapsed for a fixed distance) will be influenced by both aerobic and anaerobic energy systems. As our commentary summarizes, there is emerging literature to suggest that estimating CS provides a high-level prediction of $\dot{\mathrm{VO}}_{2 \max }$.

\section{Investigation of the FitBit Charge 2 (FBC2) device}

As new wearable technology emerges, empirical insight into usable fitness metrics such as accuracy for estimating $\dot{\mathrm{V}} \mathrm{O}_{2 \max }$ is warranted. We commend Freeberg et al. (1) for their recent investigation of the $\mathrm{FBC} 2$ device and the manufacturer's protocol for estimating "true" $\dot{\mathrm{V}} \mathrm{O}_{2 \max }$. The investigators compared the cardio fitness score from the FBC2 device with "true" $\dot{\mathrm{V}} \mathrm{O}_{2 \max }$ as measured with an incremental exercise test on a treadmill with a subsequent exhaustive verification bout. Interestingly, the authors observed that a nonexercising equation (N-EX) for estimating $\dot{\mathrm{VO}}_{2 \max }$ was more accurate than the FBC2 device. Such an observation would suggest that more information imputed to a regression model for estimating $\dot{\mathrm{V}} \mathrm{O}_{2 \max }$ may not necessarily be better. In the case of the Freeberg et al. article, their conclusion was that the accuracy of the FBC2 may have been harmed by the inclusion of exercising HR into the regression model which may explain the statistically consistent overestimation of "true" $\mathrm{VO}_{2 \max }$ that was observed. Such a result begs the question: What should wearable technology companies use to best estimate $\dot{\mathrm{VO}}_{2 \text { max }}$ ?

Our editorial commentary focuses on three areas: (I) what wearable technology manufacturers might consider when developing a device, such as the FBC2, and protocol for estimating $\dot{\mathrm{VO}}_{2 \max }$, (II) the influence of $\mathrm{HR}$ to introduce error in the estimation of $\dot{\mathrm{VO}}_{2 \max }$, and (III) the benefits and limitations of the N-EX equation for estimating $\dot{\mathrm{V}}_{2 \max }$.

(I) The protocol for the FBC2 (i.e., a minimum 10 minutes run) relies principally on time and distance recordings along with exercising HR. Time-trial performances that "dump" into a regression formula to predict $\mathrm{V}_{2 \max }$ are influenced by both aerobic and anaerobic energetic systems, the latter system being dismissed. A recent protocol, the 3-min all-out exercise test for running (2), takes into account both CS, a mechanical metric for delineating whether $\dot{\mathrm{V}} \mathrm{O}_{2}$ will steady-state or climb toward $\dot{\mathrm{V}} \mathrm{O}_{2 \max }(3)$, and the finite capacity for running at speeds 
exceeding CS (D'). Indeed, a recent study demonstrated that in comparison to the Yo-Yo intermittent test, the CS metric measured using the $3 \mathrm{MT}$ was more strongly correlated with "true" $\dot{V O}_{2 \max }$ than the Yo-Yo equation (4). That result was most likely due to the fact that the $3 \mathrm{MT}$ can parcel out the contribution of D' to a time-trial performance whereas the regression model for the Yo-Yo test assumes the total time-trial performance is supported solely by one's maximal aerobic power (MAP).

(II) The inclusion of HR response to predict $\dot{\mathrm{V}} \mathrm{O}_{2 \max }$ can introduce errors in many forms. In most submaximal exercise tests, the user extrapolates a maximal work rate based on a patient's age-predicted heart rate maximum (APHRM) and estimates $\dot{\mathrm{VO}}_{2 \max }$ using a metabolic equation (5). It is well known that "true" $H R_{\max }$ can vary from APHRM (6). Moreover, in the case of the present study by Freeberg et al. (1), introducing exercising HR data in response to speed-time data, was arguably adding "noise" to the estimation of "true" $\dot{\mathrm{V}} \mathrm{O}_{2 \max }$. These investigators extrapolated an expected exercising HR from a series of laboratory tests (i.e., the observed HR values evoked for the outdoor test using the $\mathrm{FBC} 2$ were compared with expected HR values extrapolated by constant-paced treadmill bouts). Small metabolic differences exist between treadmill and overground running (7), which we assume the authors took into consideration. That stated, the average difference was a 28 bpm underestimation during FBC2 test compared to expected HR values extrapolated from laboratory testing, implying that the FBC2 test made the subjects appear more aerobically fit than they actually were. The magnitude of HR error observed in the present study is consistent with other studies reporting underestimations of HR with wristworn HR monitors $(8,9)$.

Notably, we are not advocating that manufacturers of wearable technology abandon the ability to concurrently measure HR. Although inclusion of HR in models to predict $\dot{\mathrm{V}}{ }_{2 \max }$ may be problematic, the ability to monitor HR relative to training speeds on a workout-to-workout basis adds value. The use of HR can provide an index of internal load (i.e., how hard a workout is on a given day) (10). The use of HR can also help in monitoring training improvements. For instance, improvements in mechanical efficiency as measured by lactate threshold (LT) at a given intensity will result in a lower exercising HR at a given speed; yet, HR associated with LT will remain stable (11).

(III) As stated, the present study observed that the N-EX equation predicted $\dot{\mathrm{V}} \mathrm{O}_{2 \max }$ more accurately than the $\mathrm{FBC} 2$ protocol. The N-EX model accounts for age, sex, body mass index, and self-reported physical activity rating (PA-R) (12). The present study used a PA-R scale of 0-7; however, more recent iterations ranging 0-10 (13), and more recently $0-15$ has been reported for cycle ergometry $(14,15)$ and treadmill exercise (16). A PA-R scale with a wider range of choices may increase the fidelity of the $\dot{\mathrm{V}} \mathrm{O}_{2 \max }$ estimation across a wider range of fitness levels.

The benefit of predicting $\dot{\mathrm{V}}_{2 \max }$ with a N-EX equation is to subsequently estimate a power output or speed and/ or grade combination evoking MAP using a reversal of metabolic equations published in the American College of Sports Medicine Guidelines Manual (5) [N.B., for review on the customized procedure for incremental exercise testing, see reference (17)]. Knowing an estimate of MAP, customized incremental grades or slopes with target protocol duration times (e.g., 10 minutes) can be derived, along with customized submaximal exercise tests $(15,16)$. The limitations of the N-EX method is the lack of research on its ability to validly detect training adaptations. Thus, wearable technology may serve to inherently fill such practical gap of detecting meaningful training adaptations to an exercise program, and do so at an affordable price.

\section{Summary}

In summary, we appreciate the opportunity to provide commentary on the original investigation by Freeberg et al. (1). We commend the authors for their important work and hope that our comments provide ideas for research and development of new technology along with testing methodology on existing wearable technology. In the present study, the authors concluded the N-EX method was superior to the fitness test developed for the FBC2, with the results from the $\mathrm{FBC} 2$ device over-predicting "true" $\dot{\mathrm{V}} \mathrm{O}_{2 \max }$. Arguably, a better protocol and regression model that parcels out the contribution of D' might easily remedy such an error, although more research is warranted.

\section{Acknowledgments}

Funding: None.

\section{Footnote}

Provenance and Peer Review: This article was commissioned by the editorial office, mHealth. The article did not undergo external peer review.

Conflicts of Interest: All authors have completed the ICMJE 
uniform disclosure form (available at http://dx.doi. org/10.21037/mhealth.2020.01.03). The authors have no conflicts of interest to declare.

Ethical Statement: The authors are accountable for all aspects of the work in ensuring that questions related to the accuracy or integrity of any part of the work are appropriately investigated and resolved.

Open Access Statement: This is an Open Access article distributed in accordance with the Creative Commons Attribution-NonCommercial-NoDerivs 4.0 International License (CC BY-NC-ND 4.0), which permits the noncommercial replication and distribution of the article with the strict proviso that no changes or edits are made and the original work is properly cited (including links to both the formal publication through the relevant DOI and the license). See: https://creativecommons.org/licenses/by-nc-nd/4.0/.

\section{References}

1. Freeberg KA, Baughman BR, Vickey T, et al. Assessing the ability of the Fitbit Charge 2 to accurately predict VO2max. mHealth 2019;5:39.

2. Pettitt RW, Jamnick N, Clark IE. 3-min all-out exercise test for running. Int J Sports Med 2012;33:426-31.

3. Poole DC, Burnley M, Vanhatalo A, et al. Critical power: An important fatigue threshold in exercise physiology. Med Sci Sports Exerc 2016;48:2320-34.

4. Kramer M, Watson M, Du Randt R, et al. Critical Speed as a Measure of Aerobic Fitness for Male Rugby Union Players. Int J Sports Physiol Perform 2019;14:518-24.

5. ACSM's Guidelines for Exercise Testing and Prescription. 10th edition. Baltimore: Lippicott, Williams, \& Wilkins, 2018.

6. Tanaka H, Monahan KD, Seals DR. Age-predicted maximal heart rate revisited. J Am Coll Cardiol

doi: $10.21037 /$ mhealth.2020.01.03

Cite this article as: Pettitt RW, Fretti SK, Kantor MA, Gubler C. Using wearable technology to monitor exercise intensity and predict $\dot{\mathrm{VO}}_{2 \max }$. mHealth 2021;7:19.
2001;37:153-6.

7. Jones AM, Doust JH. A $1 \%$ treadmill grade most accurately reflects the energetic cost of outdoor running. J Sports Sci 1996;14:321-7.

8. Bunn JA, Navalta JW, Fountaine CJ, et al. Current State of Commercial Wearable Technology in Physical Activity Monitoring 2015-2017. Int J Exerc Sci 2018;11:503-15.

9. Etiwy M, Akhrass Z, Gillinov L, et al. Accuracy of wearable heart rate monitors in cardiac rehabilitation. Cardiovasc Diagn Ther 2019;9:262-71.

10. Soligard T, Schwellnus M, Alonso JM, et al. How much is too much? (Part 1) International Olympic Committee consensus statement on load in sport and risk of injury. $\mathrm{Br}$ J Sports Med 2016;50:1030-41.

11. Foster C, Fitzgerald DJ, Spatz P. Stability of the blood lactate-heart rate relationship in competitive athletes. Med Sci Sports Exerc 1999;31:578-82.

12. Jackson AS, Blair SN, Mahar MT, et al. Prediction of functional aerobic capacity without exercise testing. Med Sci Sports Exerc 1990;22:863-70.

13. George JD, Stone WJ, Burkett LN. Non-exercise VO2max estimation for physically active college students. Med Sci Sports Exerc 1997;29:415-23.

14. Dicks ND, Jamnick NA, Murray SR, et al. Load Determination for the 3-min All-Out Exercise Test for Cycle Ergometry. Int J Sports Physiol Perform 2016;11:197-203.

15. Jamnick NA, By S, Pettitt CD, et al. Comparison of the YMCA and a Custom Submaximal Exercise Test for Determining VO2max. Med Sci Sports Exerc 2016;48:254-9.

16. Strom CJ, Pettitt RW, Krynski LM, et al. Validity of a customized submaximal treadmill protocol for determining VO2max. Eur J Appl Physiol 2018;118:1781-7.

17. Pettitt RW, Clark IE, Ebner SM, et al. Gas exchange threshold and VO2max testing for athletes: an update. J Strength Cond Res 2013;27:549-55. 